
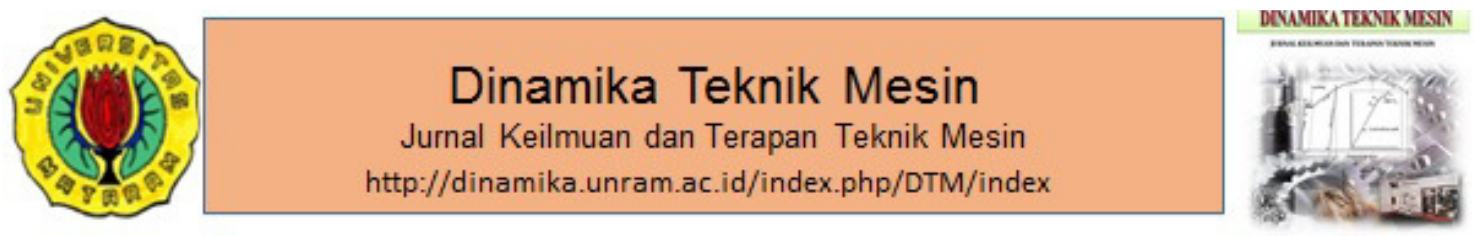

\title{
Pengaruh model reflektor terhadap performa kolektor tabung dengan phase change material
}

\section{Effect of reflector models on tube collector performance with phase change materials}

\section{M.F. Tsani ${ }^{*}$, H. Sutjahjono, M. Darsin}

Jurusan Teknik Mesin, Fakultas Teknik, Universitas Jember, Jl. Kalimantan no. 37, Jember, Jawa Timur, 68121, Indonesia. HP. 085335439291

*E-mail: farobitsani @unej.ac.id

\section{ARTICLE INFO}

Article History:

Received 20 May 2019

Accepted 20 December 2019

Available online 1 April 2020

\section{Keywords:}

Tube collector

Models

Reflector

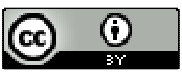

\section{ABSTRACT}

\begin{abstract}
Energy is a primary need for humans which until now is still sourced from fossil fuels. The use of solar energy as alternative energies can be used as a water heater. This shows that innovation is needed in improving the performance of the water heater collector by modeling the reflector with the intention of the temperature and efficiency produced by the water heater collector can increase. The purpose of this study was to determine the effect of the reflector model on tube collector performance. The reflector model used in this study is the U-double and U-single forms. Testing is done by heating the collector for 4 hours. The results of this study indicate that the water temperature increase in the collector with a double $U$ reflector is faster than that of a collector with a U-single reflector. The highest efficiency produced is $33.1 \%$ in collector with double $U$, while the highest $U$-single efficiency is $25.3 \%$. This shows that the $U$-double reflector model is able to improve collector performance better than the U-single reflector because the intensity of radiation reflected by the U-double reflector is greater than the $U$-single.
\end{abstract}

\section{PENDAHULUAN}

Energi merupakan kebutuhan primer bagi manusia. Hingga saat ini sumber energi utama masih dari bahan bakar fosil. Semakin meningkatnya populasi manusia dan semakin menipisnya persediaan bahan bakar fosil, mengakibatkan ketidakstabilan antara kebutuhan dan sumber energi. Maka diperlukan sumber energi baru yang jumlahnya tidak terbatas, salah satunya yaitu energi matahari. Khususnya di Indonesia yang berada di garis khatulistiwa, mendapatkan pencahayaan matahari sepanjang tahun, maka pengembangan dan riset energi matahari sangat diperlukan. 
Dinamika Teknik Mesin. Tsani dkk.: Pengaruh model reflektor terhadap performa kolektor tabung dengan phase change material

Kebutuhan energi total di Indonesia pada sektor industri diperkirakan mencapai 1221,728 PetaJoule pada tahun 2050, kemudian pada sektor transportasi mencapai 953,952 PetaJoule, sektor rumah tangga 405,848 PetaJoule dan komersial 263,592 PetaJoule (Nugraha, 2016). Sektor industri memberikan permintaan energi yang sangat besar pada tiap tahunnya. Menurut Myson (2018) bahwa industri pariwisata sektor perhotelan termasuk dalam sektor komersial yang berkontribusi terhadap penggunaan energi nasional sebesar 3\% dengan laju pertumbuhan sebesar $8,6 \%$ per tahun. Energi matahari seringkali digunakan sebagai pembangkit listrik atau pemanas air. Pemanas air domestik merupakan aplikasi yang sangat baik jika dapat digandengkan dengan penggunaan energi surya (Putra dkk., 2015).

Pemanas air surya menggunakan alat yang disebut kolektor sebagai media penyerap panas dari radiasi matahari. Kolektor pemanas air umumnya ada 2 tipe yaitu kolektor pelat datar dan kolektor tabung. Salah satu keuntungan dari kolektor surya tabung yaitu sinar matahari yang ditangkap tidak hanya sinar yang terfokuskan, namun sinar hamburan mampu ditangkap oleh kolektor ini (Papadimitratos dkk., 2016). Performa dari kolektor dapat ditingkatkan dengan cara menambahkan reflektor. Compound parabolic concentrator (CPC) dirancang sesuai dengan prinsip optik dengan fokus rendah. Sinar matahari dapat difokuskan dalam rentang tertentu dari sudut datang sinar sehingga konsentrator dapat menerima cahaya langsung dan hamburan (Su dkk., 2017).

\section{METODE PENELITIAN}

Penelitian ini dilakukan pada skala laboraturium. Susunan komponen dari kolektor tabung pemanas air surya disajikan pada gambar 1. Pada penelitian ini fluida kerja yang digunakan yaitu air dengan debit 0,04 liter/detik. Untuk sistem kolektor menggunakan sirkulasi dimana fluida yang telah dipanaskan disimpan pada bak kemudian dipanaskan kembali. Volume air yang digunakan sebanyak 5 liter. Half acceptance-angle pada reflektor U-ganda sebesar $50^{\circ}$ dan reflektor U-tunggal sebesar $72,5^{\circ}$ dengan lebar masing-masing reflektor $30 \mathrm{~cm}$. Sumber cahaya berasal dari tiga buah lampu halogen sebagai pengganti cahaya matahari. Proses pemanasan dilakukan selama 240 menit dengan interval waktu pengambilan data per 20 menit. Variabel terikat atau variabel yang dapat dihitung dan dicari nilainya yang dipengaruhi karena adanya variabel bebas yaitu suhu air keluar dari kolektor tabung pemanas. Alat dan bahan penelitian disajikan pada tabel 1 dan gambar 2 merupakan letak pengukuran suhu kolektor tabung pemanas air.

Tabel 1. Alat dan bahan

\begin{tabular}{ll}
\hline Nama & Spesifikasi \\
\hline Pipa tembaga & $\varnothing 51,4 \times 1000 \mathrm{~mm}$ dan $\varnothing 12,7 \times 2000 \mathrm{~mm}$ \\
Cover tabung & Bahan akrilik, panjang x lebar x tebal = $1000 \times 80 \times 8$ \\
& mm \\
Pompa & JP-062 \\
Pyranometer & SM206 \\
Thermocouple & Tipe K \\
Valve & Ukuran 3/8" tipe ball valve \\
Lampu halogen & Daya 1000 Watt \\
Reflektor & Bahan pelat stainless steel \\
Phase change materials & Minyak goreng dengan prosentase $30 \%$ dan parafin \\
& $70 \%$ \\
\hline
\end{tabular}

Sistem dikatakan bekerja dengan baik atau tidak, dapat diketahui dengan nilai efisiensi sistem tersebut. Efisiensi kolektor ketika proses pemanasan yaitu perbandingan antara panas yang diserap oleh fluida kerja dengan radiasi sinar yang diserap oleh luasan kolektor tersebut (Ma dkk., 2010). Efisiensi kolektor dapat dihitung menggunakan persamaan 1 (Mishra dkk., 2017):

$\eta=\frac{Q}{N A I}$

dengan $Q$ adalah kalor yang diserap (Watt), $N$ adalah jumlah kolektor, $A$ adalah luasan cover dari kolektor $\left(\mathrm{m}^{2}\right)$, I adalah intensitas radiasi $\left(\mathrm{W} / \mathrm{m}^{2}\right)$. Kalor yang diserap oleh kolektor $(Q)$ dapat dihitung menggunakan persamaan 2: 
Dinamika Teknik Mesin. Tsani dkk.: Pengaruh model reflektor terhadap performa kolektor tabung dengan phase change material

$Q=\dot{m} C_{p}\left(T_{\text {out }}-T_{\text {in }}\right)$

dengan $Q$ adalah kalor yang diserap (watt), $\dot{m}$ adalah laju aliran massa $(\mathrm{kg} / \mathrm{s}), C_{p}$ adalah kalor jenis fluida kerja $\left(\mathrm{J} / \mathrm{kg}^{\circ} \mathrm{C}\right), T_{\text {out }}$ adalah suhu air keluar dari kolektor $\left({ }^{\circ} \mathrm{C}\right)$, dan $T_{\text {in }}$ adalah suhu air masuk ke kolektor $\left({ }^{\circ} \mathrm{C}\right)$.

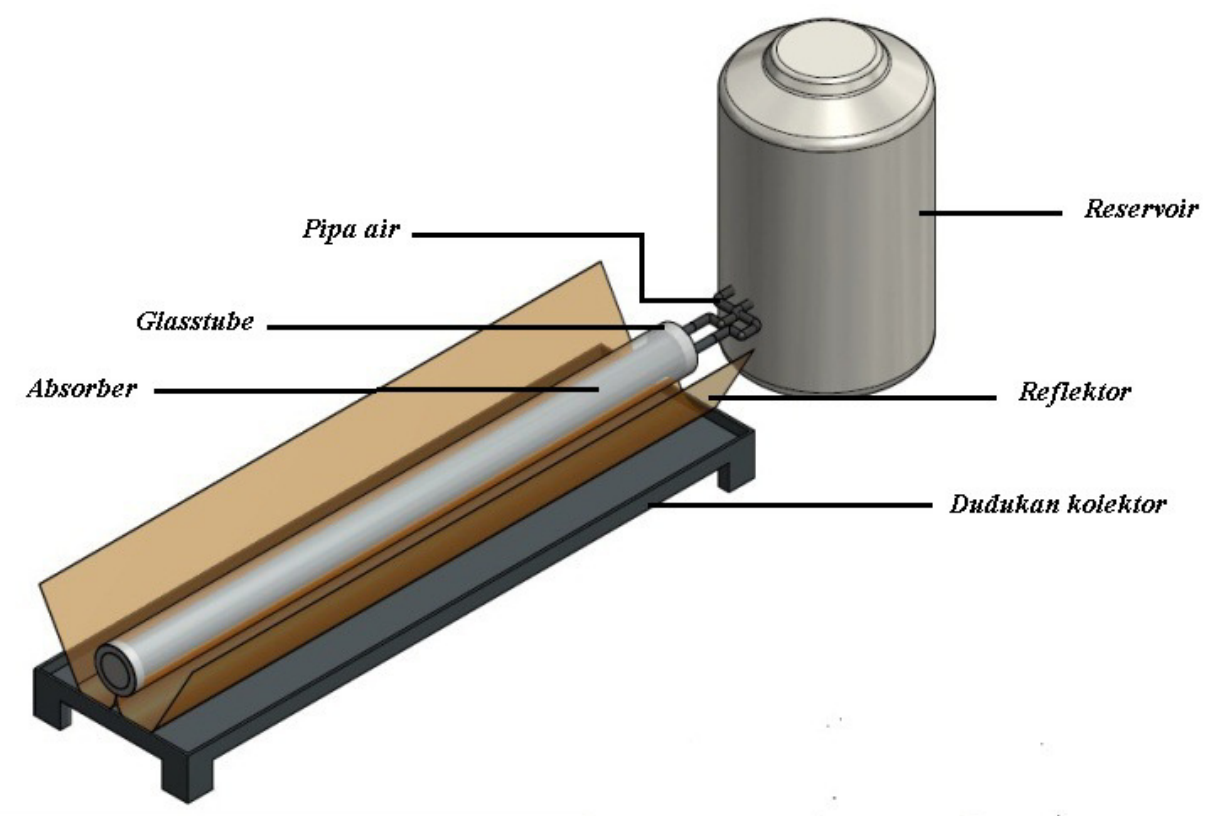

Gambar 1. Desain kolektor tabung pemanas air

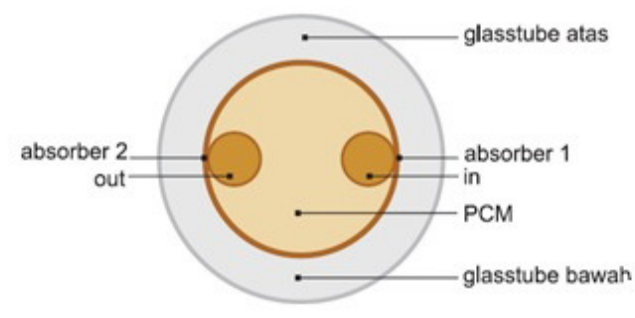

Gambar 2. Letak thermocouple pada kolektor tabung pemanas air

\section{HASIL DAN PEMBAHASAN}

Pada penelitian yang dilakukan Khavivi (2019) menyatakan bahwa penambahan reflektor pada kolektor tabung surya mampu meningkatkan efisieni sebesar $7.1 \%$ dibanding tanpa reflektor. González dkk. (2014) menjelaskan bahwa kolektor dengan menggunakan reflektor U-ganda mampu menghasilkan kenaikan temperatur maksimal $7{ }^{\circ} \mathrm{C}$ pada laju aliran massa $2 \mathrm{~kg} / \mathrm{menit}$ dan energi tertinggi yang dihasilkan bernilai $1,47 \mathrm{~kW}$ pada laju aliran massa $12 \mathrm{~kg} / \mathrm{menit}$. Waghmare dan Gulhane (2018) juga melakukan penlitian tentang pengaruh ketinggian receiver terhadap efisiensi termal dengan reflektor U-tunggal. Efisiensi tertinggi mencapai 70\% dengan ketinggian receiver 335 $\mathrm{mm}$ dan debit 30 liter/menit. Sudut datang sinar, intensitas radiasi, luasan reflektor merupakan hal yang perlu diperhatikan dalam menentukan CPC.

Merujuk dari performa kolektor dari penelitian sebelumnya, maka penelitian ini dilakukan untuk mengetahui performa kolektor pemanas air dengan menggunakan reflektor U-ganda dan U-tunggal. 
Dinamika Teknik Mesin. Tsani dkk.: Pengaruh model reflektor terhadap performa kolektor tabung dengan phase change material

Didapatkan hasil dari suhu air keluaran kolektor pemanas air dengan reflektor U-ganda dan U-tunggal disajikan pada tabel 2 dan gambar 3.

Suhu air dengan menggunakan reflektor U-ganda menghasilkan suhu yang lebih tinggi dibandingan dengan reflektor U-tunggal Suhu tertinggi yang dihasilkan dari kolektor dengan reflektor U-ganda yaitu $60,1^{\circ} \mathrm{C}$ dan kolektor dengan reflektor U-tunggal yaitu $57,7^{\circ} \mathrm{C}$. Hal ini dikarenakan reflektor U-ganda mampu memfokuskan sinar lebih baik dibanding reflektor U-tunggal. Pemfokusan sinar berpengaruh terhadap nilai intensitas radiasi pantulan yang dihasilkan. Semakin besar intensitas sinar pantulan maka semakin tinggi pula suhu yang dihasilkan. Suhu air keluaran dari penelitian ini lebih tinggi dibandingkan hasil penelitian yang dilakukan oleh Khavivi (2019) yaitu sebesar 52,4 $\mathrm{C}^{\circ}$ pada kolektor dengan reflektor dan kolektor tanpa reflektor yaitu $44,6 \mathrm{C}^{\circ}$.

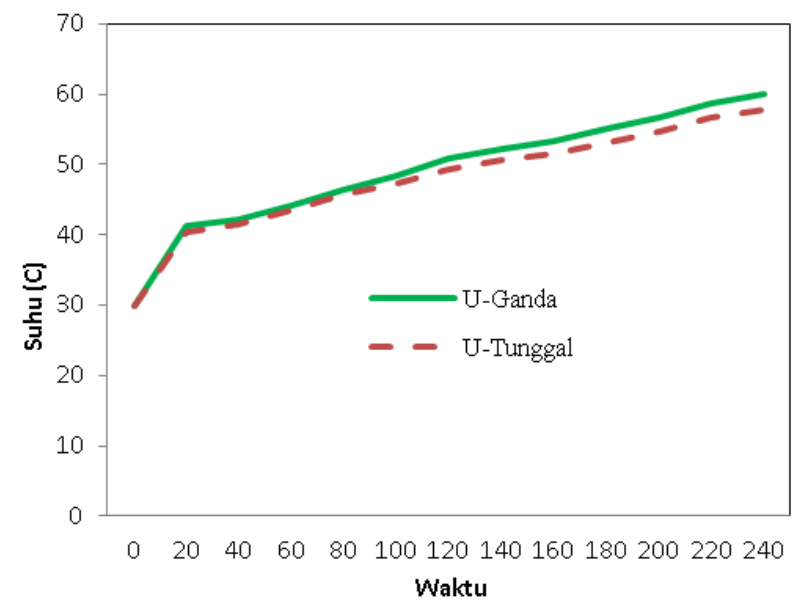

Gambar 3. Suhu PCM - air keluar saat proses pemanasan

Efisiensi pada penelitian ini diambil ketika proses pemanasan. Debit $(\dot{m})$ menggunakan 0,04 liter/detik, nilai $C p$ air adalah 4200 Joule dan luas cover $(A) 0,0251 \mathrm{~m}^{2}$ dan $\Delta T$ merupakan selisih suhu air keluar dengan suhu air masuk kolektor $\left({ }^{\circ} \mathrm{C}\right)$. Data nilai efisiensi kolektor tabung pemanas air yang dihitung berdasarkan persamaan 1 disajikan pada tabel 3 dan 4. Grafik pengaruh intensitas cahaya terhadap efisiensi ditampilkan pada gambar 4.

Tabel 2. Suhu air ketika proses pemanasan

\begin{tabular}{cccc}
\hline $\begin{array}{c}\text { Waktu } \\
\text { (menit) }\end{array}$ & $\begin{array}{c}\mathrm{I} \\
\left(\mathrm{W} / \mathrm{m}^{2}\right)\end{array}$ & $\begin{array}{c}\mathrm{T}_{\text {air }} \mathrm{UG} \\
\left({ }^{\circ} \mathrm{C}\right)\end{array}$ & $\begin{array}{c}\mathrm{T}_{\text {air }} \mathrm{UT} \\
\left({ }^{\circ} \mathrm{C}\right)\end{array}$ \\
\hline 0 & 750,0 & 30,0 & 30,0 \\
20 & 744,2 & 41,3 & 40,3 \\
40 & 740,5 & 42,2 & 41,4 \\
60 & 778,7 & 44,1 & 43,5 \\
80 & 798,7 & 46,4 & 45,8 \\
100 & 817,7 & 48,5 & 47,3 \\
120 & 791,0 & 50,8 & 49,2 \\
140 & 729,7 & 52,2 & 50,6 \\
160 & 732,2 & 53,3 & 51,6 \\
180 & 808,0 & 55,1 & 53,2 \\
200 & 793,7 & 56,7 & 54,7 \\
220 & 823,2 & 58,7 & 56,6 \\
240 & 809,0 & 60,1 & 57,7 \\
\hline
\end{tabular}

Semakin besar intensitas radiasi yang diberikan maka efisiensi dari kolektor juga semakin meningkat. Efisiensi tertinggi dihasilkan dari kolektor dengan reflektor U-ganda. Pada menit 240 yaitu sebesar $33,1 \%$. Sedangkan efisiensi tertinggi yang dihasilkan kolektor dengan reflektor U-tunggal 
Dinamika Teknik Mesin. Tsani dkk.: Pengaruh model reflektor terhadap performa kolektor tabung dengan phase change material

yaitu sebesar $25,3 \%$ pada menit 200 . Efisiensi tertinggi dari masing-masing kolektor berada di waktu yang berbeda. Hal ini dikarenakan intensitas radiasi yang diterima kolektor berbeda-beda. Meski selama penelitian intensitas radiasi naik turun, namun efisiensi yang dihasilkan kolektor dengan Uganda cenderung stabil. Hal ini disebabkan reflektor U-ganda mampu mengoptimalkan sinar radiasi dari lampu. Selain intensitas radiasi berdasarkan persamaan 1, ada faktor lain yang dapat mempengaruhi efisiensi dari kolektor tabung ini yaitu laju aliran massa, fluida yang digunakan, jumlah kolektor dan luasan dari cover kolektor.

Tabel 3. Efisiensi kolektor tabung pemanas air dengan reflektor U-ganda

\begin{tabular}{crrr}
\hline $\begin{array}{c}\text { Waktu } \\
\text { (menit) }\end{array}$ & $\begin{array}{c}\mathrm{I} \\
\left(\mathrm{W} / \mathrm{m}^{2}\right)\end{array}$ & $\begin{array}{c}\Delta \mathrm{T}_{\text {air }} \\
\left({ }^{\circ} \mathrm{C}\right)\end{array}$ & $\begin{array}{c}\eta \\
(\%)\end{array}$ \\
\hline 0 & 750,0 & 0 & 0,00 \\
20 & 744,2 & 0,2 & 17,97 \\
40 & 740,5 & 0,2 & 18,06 \\
60 & 778,7 & 0,2 & 17,17 \\
80 & 798,7 & 0,3 & 25,12 \\
100 & 817,7 & 0,3 & 24,53 \\
120 & 791,0 & 0,3 & 25,36 \\
140 & 729,7 & 0,2 & 18,33 \\
160 & 732,2 & 0,2 & 18,26 \\
180 & 808,0 & 0,3 & 24,83 \\
200 & 793,7 & 0,3 & 25,27 \\
220 & 823,2 & 0,4 & 32,49 \\
240 & 809,0 & 0,4 & 33,06 \\
\hline
\end{tabular}

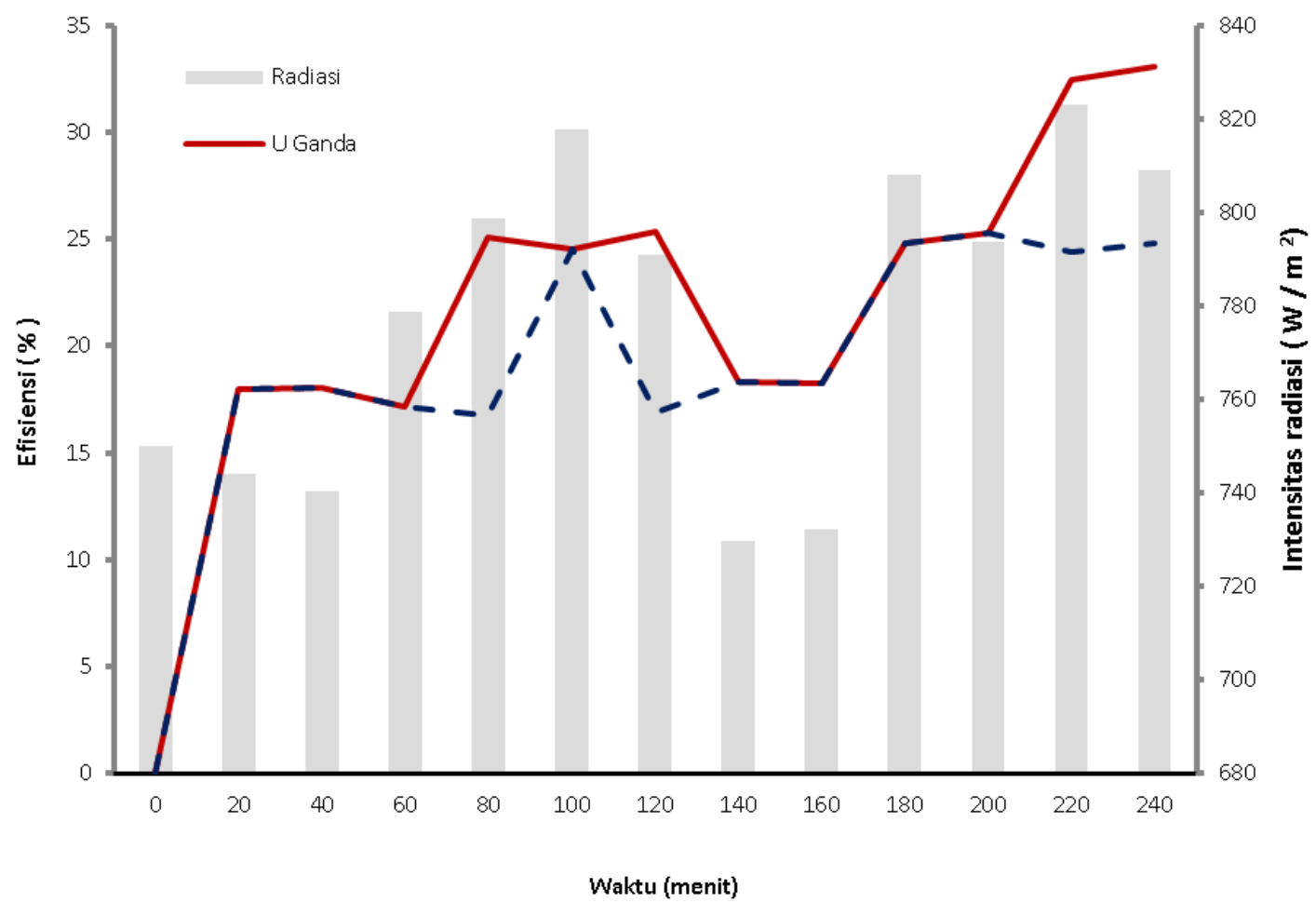

Gambar 4. Efisiensi kolektor tabung pemanas air ketika proses pemanasan.

Hasil penelitian ini memberikan kontribusi bahwa belum ada penelitian terpublikasi yang membahas keterkaitan antara model reflektor terhadap performa dari kolektor tabung pemanas air. Penelitian ini bisa dijadikan sumber literasi guna penelitian dari performa kolektor pemanas air surya. 
Dinamika Teknik Mesin. Tsani dkk.: Pengaruh model reflektor terhadap performa kolektor tabung dengan phase change material

Tabel 4. Efisiensi kolektor tabung pemanas air dengan reflektor U-tunggal

\begin{tabular}{crrr}
\hline $\begin{array}{c}\text { Waktu } \\
\text { (menit) }\end{array}$ & $\begin{array}{c}\mathrm{I} \\
\left(\mathrm{W} / \mathrm{m}^{2}\right)\end{array}$ & $\begin{array}{c}\Delta \mathrm{T}_{\text {air }} \\
\left({ }^{\circ} \mathrm{C}\right)\end{array}$ & $\begin{array}{c}\mathrm{n} \\
(\%)\end{array}$ \\
\hline 0 & 750,0 & 0 & 0,00 \\
20 & 744,2 & 0,2 & 17,97 \\
40 & 740,5 & 0,2 & 18,06 \\
60 & 778,7 & 0,2 & 17,17 \\
80 & 798,7 & 0,2 & 16,74 \\
100 & 817,7 & 0,3 & 24,53 \\
120 & 791,0 & 0,2 & 16,91 \\
140 & 729,7 & 0,2 & 18,33 \\
160 & 732,2 & 0,2 & 18,27 \\
180 & 808,0 & 0,3 & 24,83 \\
200 & 793,7 & 0,3 & 25,27 \\
220 & 823,2 & 0,3 & 24,37 \\
240 & 809,0 & 0,3 & 24,80 \\
\hline
\end{tabular}

\section{KESIMPULAN}

Berdasarkan hasil penelitian yang telah dilakukan bahwa performa kolektor tabung dengan reflektor U-ganda menghasilkan suhu air lebih tinggi dibandingkan dengan kolektor dengan reflektor U-tunggal dikarenakan pemfokusan sinar lebih baik. Dengan begitu efisiensi yang dihasilkan kolektor dengan reflektor U-ganda lebih baik dibandingkan dengan kolektor dengan reflektor U-tunggal.

\section{UCAPAN TERIMAKASIH}

Penulis pada kesempatan ini mengucapkan terimakasih kepada kolega penelitian, Khamdan, Veni, Bella, Bowo yang telah membantu baik berupa materi maupun pikiran sehingga penelitian dan paper ini dapat terselesaikan.

\section{DAFTAR NOTASI}

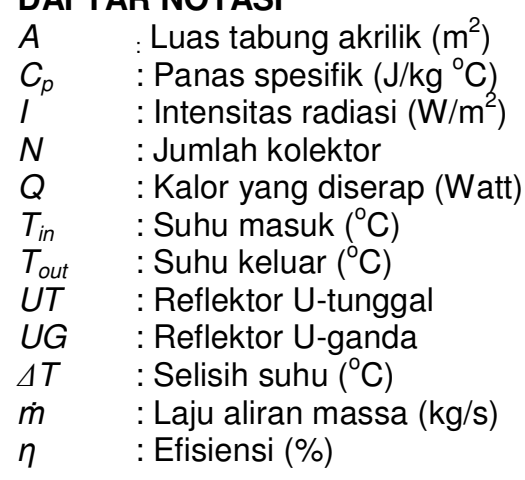

\section{DAFTAR PUSTAKA}

González I.S., Reyes M.S., Valladares O.G., Ortega N., Gómez V.H., 2014, Design and evaluation of a compound parabolic concentrator for heat generation of thermal processes, Jurnal Energy Procedia 57, $2956-2965$.

Khavivi K., 2019, Analisis performa kolektor tabung pemanas air menggunakan phase change material (PCM) dengan dan tanpa reflektor, Skripsi, Jember: Universitas Jember.

Ma L., Lu Z., Zhang J., Liang R., 2010, Thermal performance analysis of the glass evacuated tube solar collector with U-tube, Jurnal Building and Environment 45, 1959-1967.

Mishra R.K., Garg V.A., Tiwari G.N., 2017, Energy matrices of U-shaped evacuated tubular collector (ETC) integrated with compound parabolic concentrator (CPC), Jurnal Solar Energy, 153, 531539.

Myson, 2018, Peluang efisiensi penggunaan energi pada sektor perhotelan di Kota Jambi., Jurnal Civronlit Universitas Batanghari, 3(1), 37-45.

Nugraha S., 2016, Outlook Energi Indonesia 2016, Penerbit Dewan Energi Nasional, Jakarta. 
Dinamika Teknik Mesin. Tsani dkk.: Pengaruh model reflektor terhadap performa kolektor tabung dengan phase change material

Papadimitratos A., Sobhansarbandi S., Pozdin V., Zakhidov A., Hassanipour F., 2016, Evacuated tube solar collectors integrated with phase change materials, Jurnal Solar Energy, 129, 10-19.

Putra N., Adi W., Amin M., 2015, Uji eksperimental kinerja PCM beeswax sebagai thermal storage pada aplikasi pemanas air domestic, Prosiding Seminar Nasional Tahunan Teknik Mesin XIV (SNTTM XIV).

Su Z., Gu S., Vafai K., 2017, Modeling and simulation of ray tracing for compound parabolic thermal solar collector, International Communications in Heat and Mass Transfer, 87: 169-174.

Waghmare S.A., Gulhane N.P., 2018, Optimization of receiver height in compound parabolic collector by optical analysis and experimental method, Jurnal Optics, 157, 1331-1341. 